\title{
A Novel Reporter Mouse Uncovers Endogenous Brn3b Expression
}

\author{
Adam M. Miltner ${ }^{1}$, Yesica Mercado-Ayon ${ }^{1}$, Simranjeet K. Cheema ${ }^{1}$, Pengfei Zhang ${ }^{1,2} \mathbb{D}$, \\ Robert J. Zawadzki ${ }^{2,3}$ and Anna La Torre ${ }^{1, *(D)}$
}

1 Department of Cell Biology and Human Anatomy, University of California-Davis, Davis, CA 95616, USA; ammiltner@ucdavis.edu (A.M.M.); mercadoayon@ucdavis.edu (Y.M.-A.); simcheema@ucdavis.edu (S.K.C.); pfzhang@ucdavis.edu (P.Z.)

2 UC Davis EyePod Small Animal Ocular Imaging Laboratory, University of California-Davis, Davis, CA 95616, USA; rjzawadzki@ucdavis.edu

3 Department of Ophthalmology and Vision Science, University of California-Davis, Sacramento, CA 95817, USA

* Correspondence: alatorre@ucdavis.edu; Tel.: +1-530-752-9103

Received: 25 March 2019; Accepted: 12 June 2019; Published: 14 June 2019

\begin{abstract}
Brn3b (Pou4f2) is a class-4 POU domain transcription factor known to play central roles in the development of different neuronal populations of the Central Nervous System, including retinal ganglion cells (RGCs), the neurons that connect the retina with the visual centers of the brain. Here, we have used CRISPR-based genetic engineering to generate a Brn3b-mCherry reporter mouse without altering the endogenous expression of Brn3b. In our mouse line, mCherry faithfully recapitulates normal Brn3b expression in the retina, the optic tracts, the midbrain tectum, and the trigeminal ganglia. The high sensitivity of mCherry also revealed novel expression of Brn $3 b$ in the neuroectodermal cells of the optic stalk during early stages of eye development. Importantly, the fluorescent intensity of Brn3b-mCherry in our reporter mice allows for noninvasive live imaging of RGCs using Scanning Laser Ophthalmoscopy (SLO), providing a novel tool for longitudinal monitoring of RGCs.
\end{abstract}

Keywords: retinal ganglion cells (RGCs); CRISPR-Cas9; retinal development; optic stalk; retinal imaging; scanning laser ophthalmoscopy (SLO)

\section{Introduction}

Retinal ganglion cells (RGCs) are the sole output neurons of the retina. Located along the inner surface of the retina, RGCs receive and integrate signals from the retina circuitry and send long axons that converge at the center of the eye to form the optic nerve and convey visual information to several areas of the brain [1,2]. There are approximately 40 RGC subtypes classified by single-cell RNA sequencing clustering algorithms [3], and RGCs have also been categorized into numerous subtypes based on their morphological and functional properties [4]. Different RGC populations participate in distinct circuits, but the vast majority of optic nerve axons terminate in the lateral geniculate nucleus of the thalamus or the superior colliculus in the tectum of the midbrain [5].

Progressive damage to the optic nerves and RGC degeneration is the final common pathway that leads to vision loss in glaucoma, one of the leading causes of visual impairment and blindness worldwide [6]. Although research in the field of glaucomatous degenerations is extensive, the pathophysiological mechanisms underlying these diseases are not completely understood. Rodent models of RGC degeneration have been vital to our continued efforts to understand the progression of glaucoma and to devise novel therapeutic interventions. Several invasive methods [7-14], naturally occurring models $[15,16]$, and genetic manipulations $[17,18]$ have been utilized as a proxy to 
glaucomatous disease. However, all these methods rely on in vivo optical coherence tomography scans (OCT) imaging [19] or post-mortem histological procedures to assess the degree of RGC degeneration. In general, OCT measurements of the ganglion cell complex involve measuring the thickness of three layers together: the inner plexiform layer (IPL) that contains the dendritic arbors of the RGCs and the axons of the cells of the inner nuclear layer of the retina, the ganglion cell layer (GCL) that contains the somas of the RGCs and the displaced amacrine cells, and the retinal nerve fiber layer (RNFL) containing the RGC axonal processes and astrocytes [20,21]. While great progress in segmentation algorithms has been achieved and measurements of the GCL alone are possible, albeit time-consuming, and novel imaging technologies are being developed, the current standard tools are not ideal to follow RGCs over time [22]. Similarly, several RGC reporter mice are available including Thy-XFP, Isl2-GFP, DRD4-GFP, Hoxd10-GFP and many others but these reporters are either not specific or label only a small subset of RGCs [23-29].

Previous reports have identified Brn3b (Pou4f2), a POU-4 transcription factor, as a master regulator of RGC development and neural cell type diversity [30-32]. The basic helix-loop-helix (bHLH) transcription factor Atoh7/Math5 is expressed in RGC precursors and controls the expression of Brn3b and another transcription factor, Isl1, which in a combinatorial manner are required for the initiation of the RGC program [33,34]. Consequently, deletion of Brn3b results in the loss of $70 \%$ of all RGCs, with remaining RGCs exhibiting axonal guidance defects or delays [35-40]. Conversely, overexpression of Brn3b and Isl1 together is sufficient to promote RGC fates [41]. Brn3b expression has also been observed in the trigeminal nerve ganglia and other cranial nerve nuclei in a very characteristic and dynamic spatiotemporal pattern [42,43].

Here, we have developed a murine fluorescent reporter using CRISPR-Cas9 to introduce monomeric Cherry fluorescent protein (mCherry) after the coding sequence of Brn $3 \mathrm{~b}$, without modifying its normal expression. In Brn3b-mCherry mice, mCherry closely recapitulates endogenous Brn3b expression and, as a result, labels a large proportion of RGCs. In the retina, mCherry expression begins around embryonic day 11.5 (E11.5), coinciding with the onset of RGC genesis, and persists throughout development and in the adult retina. Interestingly, our approach also revealed novel Brn3b expression in the optic stalk during early development. Additionally, the high detectability of mCherry allows for live imaging of RGCs using fluorescence detection by Scanning Laser Ophthalmoscopy (SLO), providing a powerful tool to monitor RGCs over time.

\section{Results and Discussion}

\subsection{Generation of CRISPR-Engineered Brn3b-mCherry Reporter Mouse Line}

We aimed to generate a Brn $3 \mathrm{~b}$ reporter mouse line without interfering with Brn $3 \mathrm{~b}$ endogenous expression. To that goal, we designed a CRISPR/Cas9 (Clustered Regularly Interspaced Short Palindromic Repeats/CRISPR-associated protein 9) strategy to insert 2A self-cleaving peptide (P2A) and monomeric Cherry fluorescent protein (mCherry) sequences immediately downstream of the coding sequence of the Brn3b gene (Pou4f2, transcript NM_138944, Figure 1A). The gene-targeting was completed by Biocytogen (Worcester, MA, USA). Briefly, single guide RNAs (sgRNAs) were designed using the CRISPR Finder design tool www.sanger.ac.uk [44]. One sgRNA (GGAGAAGGGTCCCTAAATGC) was selected, cloned into pT7-sgRNA by Gibson assembly, confirmed by DNA sequencing, and transcribed in vitro. Similarly, the targeting vector was constructed as shown in Figure 1A. and validated by DNA sequencing. 286 zygotes were microinjected and transferred into pseudopregnant females, from which 21 pups were born. With this strategy, a cassette containing a P2A-mCherry sequence flanked by homology arms to exon 2 of Brn3b ( $5^{\prime}$ homology) and to the $3^{\prime}$ UTR of the Brn $3 \mathrm{~b}$ coding sequence ( $3^{\prime}$ homology) were inserted by homologous recombination into the Brn3b locus. Therefore, the resulting animals express Brn $3 b$ and mCherry from the endogenous Brn $3 b$ promoter and regulatory elements. The founders were bred, the F1 animals were genotyped, and the 
positive animals were further confirmed by Southern blot using two different probes (Figure 1B) as detailed in Figure S1.

A

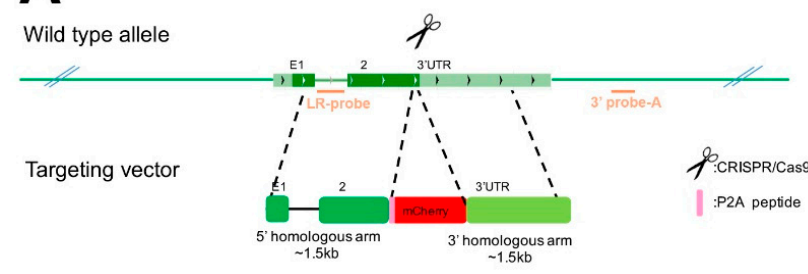

Targeted allele
B

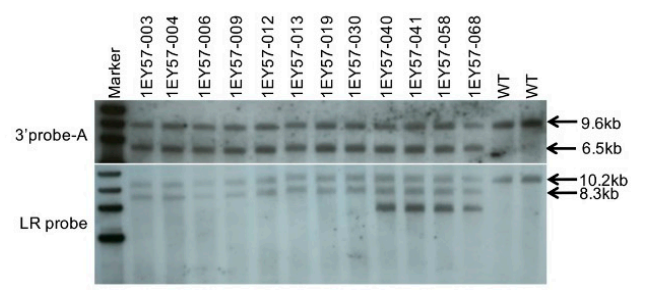

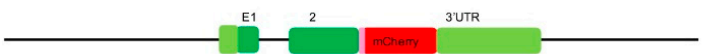

Figure 1. Design and validation of CRISPR/Cas9 strategy. (A) Schematic of the mouse Brn3b locus. The dark green boxes correspond to the two exons of Brn3b (E1/2). Two probes named LR-probe and $3^{\prime}$ probe-A (orange lines) were used to identify correctly targeted animals. (B) Southern blot of Brn3b-mCherry mice showing correct insertion of the mCherry targeting vector into the Brn $3 b$ locus. Further details on Southern blot design strategy design is detailed in Figure S1.

Other Brn3b reporter animals have been previously reported, including a GFP knock-in reporter [45] as well as numerous strategies for labeling Brn3b+ cells using Cre or Dre-driven recombination combined with alkaline phosphatase or lac $Z$ to visualize the recombined cells [46-49]. Each of these models is useful for studying RGC and retinal biology, however in all these lines at least one copy of Brn $3 b$ is disrupted. Furthermore, Brn3b is present in the germline or ubiquitously expressed in the early stages of development leading to recombination in the whole animal in some Brn3b-Cre knock-in models [49].

Similarly, other fluorescent RGC reporters using different drivers have also been developed. For example, several Thy1 reporters have been generated and are widely used. However, Thy 1 is not exclusively expressed in RGCs as many displaced amacrine cells as well as INL neurons also express Thy1 [23]. It is important to note that in our design we chose mCherry because it typically displays low autofluorescence background levels and high photostability [50]. Furthermore, our Brn3b-mCherry line could be easily combined with other existing RGC reporters such as the Thy1-YFP or Isl2-GFP mice $[23,51]$, and a similar strategy has been successfully used to label RGCs derived from human Embryonic Stem Cells [52,53].

\section{2. mCherry Labels A Large Fraction of RGCs in the Adult Retina of Brn3b-mCherry Mice}

To analyze mCherry expression in the adult retina, 8-12-week old Brn3b-mCherry mice $(n=4$ from two different generations) were euthanized, and their retinas were dissected, flat-mounted, fixed, and immunolabeled with mCherry and Brn3, as well as with other known RGC markers such as RBPMS and Tuj1 (Figure 2). mCherry+ RGC somas range from 8.25-29.67 $\mu \mathrm{m}$, with an average diameter of $15.1+/-3.6 \mu \mathrm{m}$ consistent with previous reports [29], and we observed an average of 2297 $+/-411$ mCherry+ cells $/ \mathrm{mm}^{2}$ of retina (mean +/- SD, Table S1). A widely-used pan-Brn3 antibody that detects Brn3a, Brn3b and Brn3c (C-20, Santa Cruz Biotechnology) labels most RGCs, but some subpopulations, including some intrinsically-photosensitive RGCs (ipRGCs), are Brn3- [54,55]. As expected, mCherry highly colocalizes with Brn3 (99.06 $\pm 0.25 \%$ colocalization, indicated as mean $+/-\mathrm{SD}$ ) and we only found a very small subset of Brn3+ cells that were mCherry- (yellow arrow in Figure $\left.2 \mathrm{~B}^{\prime}\right)$, presumably indicating a small fraction of cells that are Brn3b- but Brn3a+ or Brn3c+. As described previously, RBPMS specifically labels all RGCs [29]. Counting RBPMS+ and mCherry+ cells in our Brn3b-mCherry mouse indicated that $70.86 \pm 4.33 \%$ of all RGCs are mCherry+ (data indicated as mean $+/-$ SD, yellow arrows in Figure $2 C^{\prime}$ show RBPMS+ mCherry- RGCs). Conversely, $100 \%$ of mCherry+ cells are RBPMS+ indicating that all fluorescently-labeled cells are RGCs (Figure 2C, $\mathrm{C}^{\prime}$ ). 
Since the mCherry sequence does not include a nuclear localization signal, the RGC axonal bundles (Tuj1+, white arrows in Figure 2D') and optic nerves also exhibit detectable levels of mCherry.
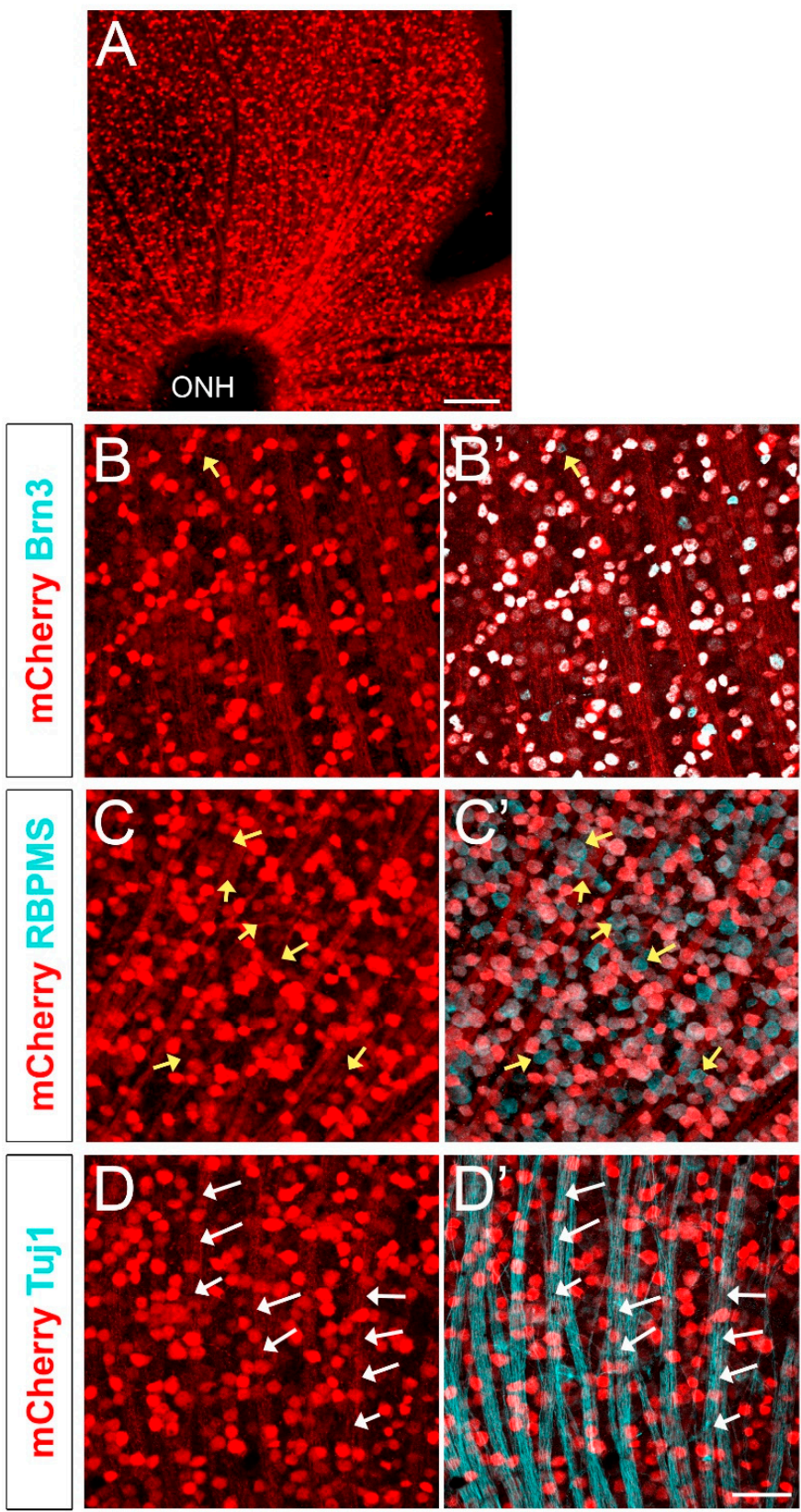

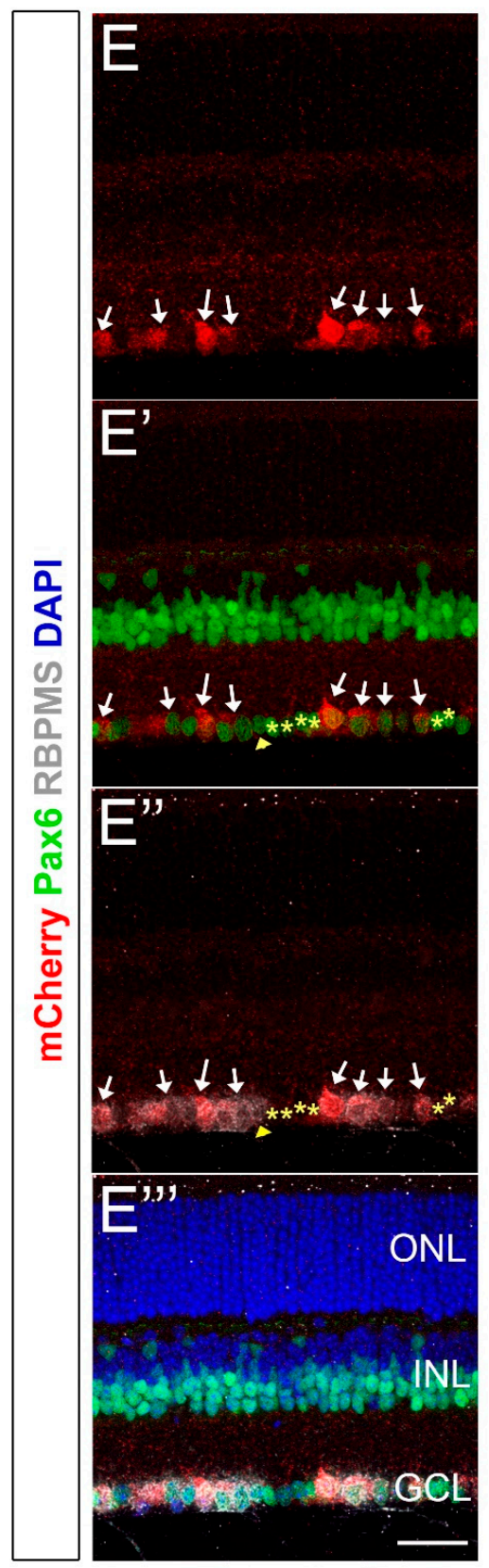

Figure 2. Brn3b-mCherry expression in the adult retina. (A) Flat-mounted retina labeled with anti-mCherry antibody. (B,B') mCherry (red) and Brn3 (teal) colocalization. Yellow arrow indicates a Brn3+ mCherry- cell. $\left(\mathbf{C}, \mathbf{C}^{\prime}\right)$ mCherry (red) and RBPMS (teal) colocalization. Yellow arrows indicate RBPMS+ mCherry- cell bodies. (D,D') mCherry (red) and Tuj1 (teal) colocalization. White arrows indicate Tuj1+ mCherry+ axons. (E-E'") Cross-section of an adult retina labeled with mCherry (red), RBPMS (gray), DAPI (blue), and Pax6 (green). All mCherry+ cells (white arrows) are RBPMS+. Amacrine cells are labeled with yellow stars and are mCherry- (Pax6+ RBPMS- mCherry- cells). Yellow arrowhead corresponds to an mCherry- RGC (RBPMS+ Pax6- mCherry-cell). ONH: Optic Nerve Head. ONL: Outer Nuclear Layer. INL: Inner Nuclear Layer. GCL: Ganglion Cell Layer. Scale bars: 300 microns in A, 50 microns in B-E"'.

Paraffin sections of Brn3b-mCherry adult mice showed specific mCherry expression only in the GCL (Figure 2E). To verify that mCherry is only expressed in RGCs and not in displaced amacrine 
cells or in any other retinal cell type, we performed co-localization experiments with Pax6 (Figure 2E') and RBPMS (2E"). Pax6 is expressed in RGCs, amacrine cells, horizontal cells, and Muller glia [56]. Therefore, Pax6+ RBPMS- cells located in the GCL are displaced amacrine cells (yellow stars in Figure $\left.2 \mathrm{E}^{\prime}, \mathrm{E}^{\prime \prime}\right)$ and these cells are not mCherry positive. Conversely, a considerable fraction of RBPMS+ cells exhibit mCherry expression (white arrows, Figure 2E-E"), similarly to our flat-mount experiments. Together, these findings suggest that our Brn3b-mCherry reporter mouse specifically labels RGCs in the adult mouse retina.

\subsection{The Expression Pattern of mCherry Recapitulates Endogenous Brn3b during Retinal Development}

During normal development, retinal progenitor cells give rise to all the different cells of the retina in a stereotyped sequence with the RGCs being the first cell population generated [57-59]. Classic $\mathrm{H}^{3}$-thymidine labeling and cell lineage experiments established that in the mouse retina the onset of RGC genesis is around embryonic day 11.5 (E11.5). We detected mCherry in our Brn3b-mCherry mouse line at the onset of Brn3b expression in nascent RGCs located in the center of the retina at E11.5 and this expression progressively spreads outward during the wave of neurogenesis that occurs during retinal development (Figure 3). At all the ages analyzed, mCherry expression colocalizes with Brn3 as observed by immunohistochemistry using mCherry and Brn3 antibodies (Figure 3A-C"). Moreover, mCherry is also observed in axonal fibers and in the optic nerve (white arrows in Figure 3B).

To define the dynamics of Brn3b expression, we performed co-localization experiments with well-established markers for different stages in RGC development. PCNA (Proliferating Cell Nuclear Antigen) is a known marker of retinal progenitor cells that labels dividing cells during all phases of cell cycle throughout retinal histogenesis [60]. Co-immunolabeling experiments of mCherry and PCNA showed that Brn3b and PCNA are largely expressed in two separate populations. This is not surprising, as Brn3b is mostly expressed in post-mitotic RGCs. However, we found a small fraction of mCherry+ cells that co-labeled for PCNA (white arrows in Figure 3D), indicating that Brn3b can be expressed in dividing progenitors, probably during the terminal cell division. Brn $3 \mathrm{~b}$ and Isl1 have been previously detected in EdU or BrdU-labeled cells after a short chase [61,62], suggesting that these transcription factors can be expressed during $S$ or G2, consistent with the hypothesis that fate commitment is decided prior to the terminal mitosis [61,63]. Atoh7 (Atonal homologue 7/formerly Math5) is expressed during the terminal cell cycle in a subset of progenitor cells and is known to be required for RGC genesis [33,34,63]. Accordingly, a subset of Atoh7+ cells co-expresses Brn3b [64,65]. As expected, in our mouse model, mCherry also overlaps with a small subpopulation of Atoh7+ cells (white arrows in Figure 3E). As the retina develops in a central to peripheral gradient, Atoh7 precedes Brn3b expression (yellow arrowhead in Figure 3E) consistent with a younger developmental status at the periphery. Therefore, the expression patterns observed support the current model of transcriptional relationships of Atoh7 and Brn3b. Finally, $\gamma$-Synuclein (sncg) is a commonly used marker of RGCs, and its expression has been shown to be RGC-specific in the adult retina and in purified postnatal RGC cultures [66-68]. All $\gamma$-Synuclein + cells are mCherry+ at E13.5 (Figure 3F) but, in this case, mCherry expression precedes $\gamma$-Synuclein (yellow arrow in Figure 3F), suggesting that $\gamma$-Synuclein is expressed in a later maturation stage during RGC development. Altogether, our data indicates that mCherry expression in our reporter mouse faithfully recapitulates spatial and temporal Brn3b patterns in the developing mouse retina. 

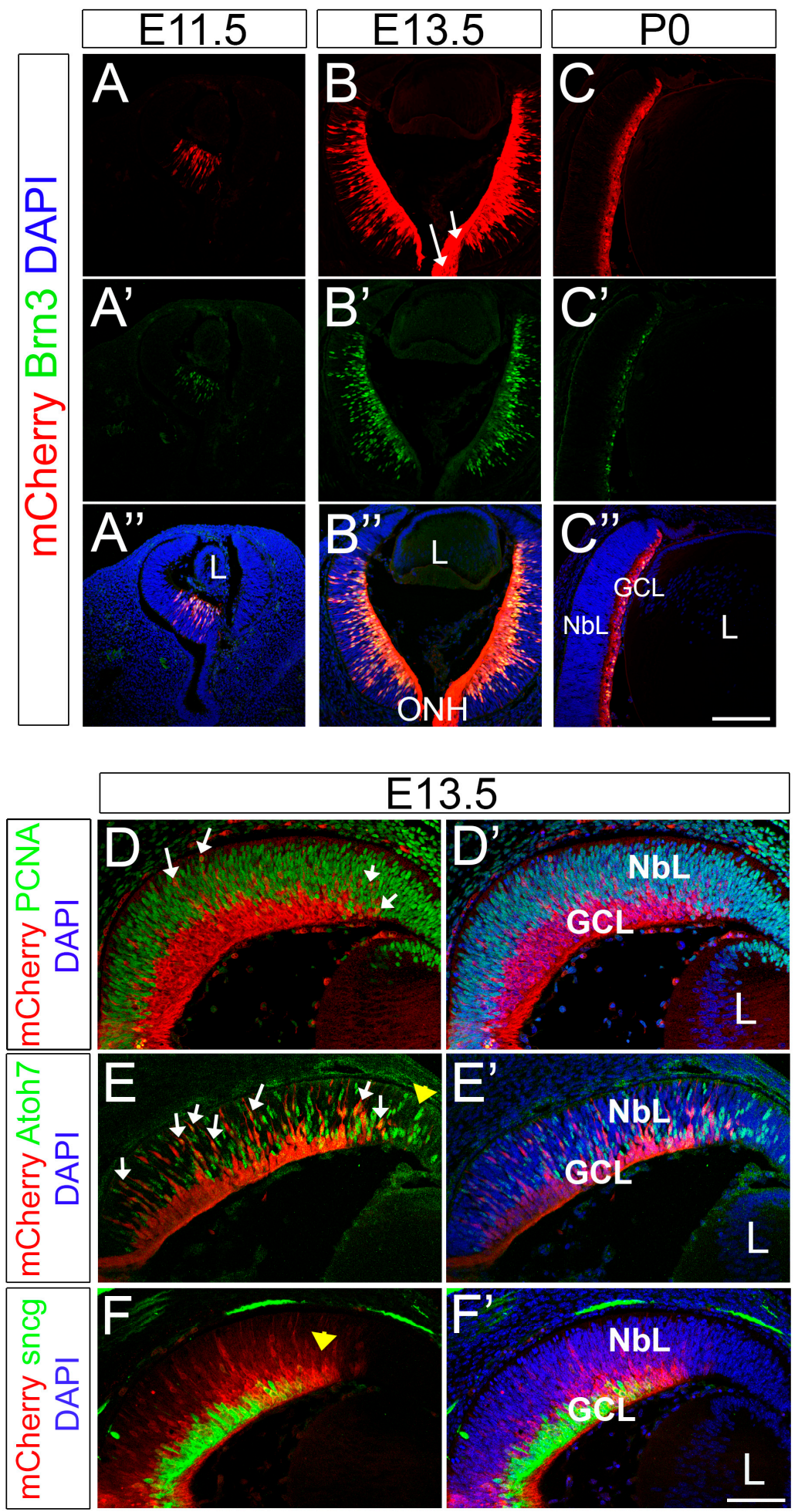

Figure 3. Brn3b-mCherry expression during early retinal development. (A-C') Co-localization experiments of mCherry and pan-Brn3 antibody at E11.5 (A-A"), E13.5 (B-B") and P0 (C-C"). White arrows in B indicate mCherry+ RGC axons. D-F') E13.5 retina stainings. (D,D') mCherry (red) and PCNA (green) co-localization. White arrows: PCNA+ mCherry+ cells. (E,E') mCherry (red) and Atoh7 (green) co-localization. White arrows: mCherry+ Atoh7+ cells. Yellow arrowhead indicates the leading edge of neurogenesis. $\left(\mathbf{F}, \mathbf{F}^{\prime}\right)$ mCherry (red) and $\gamma$-synuclein (green) colocalization. Yellow arrowhead indicates the leading edge of neurogenesis. L: Lens. NbL: Neuroblastic Layer. GCL: Ganglion Cell layer. Scale bars: 200 microns A-C', 100 microns D-F'. 


\subsection{Brn3b-mCherry Reveals the Dynamic Expression of Brn3b during CNS Development}

In addition to the expected expression in RGCs, we also validated mCherry expression in the optic nerves and optic tracts (Figure 4A). As described previously, Brn3b is also expressed in subsets of neurons of the superior colliculus, with a very $\mathrm{dim} / \mathrm{sparse}$ expression in the superior layer (stratum griseum superficiale) and very prominent expression in the putative stratum opticum, where RGC axons enter the superior colliculus at a deep level relative to the pial surface [69]. In agreement with these prior findings, we detected high levels of mCherry expression in the deeper areas of the superior colliculi, and this expression greatly colocalizes with Brn3 (Figure 4B, $B^{\prime}$ ). Furthermore, Brn3b is expressed in different cranial nerve nuclei in a very dynamic fashion. For example, Brn3b is present in subsets of neurons of the trigeminal ganglia $(\mathrm{V})$ at early stages of development [42]. Consistently, at E13.5, mCherry is present in a salt-and-pepper manner in the trigeminal ganglia in Brn3b-mCherry mice (Figure $4 \mathrm{C}, \mathrm{C}^{\prime}$ ).
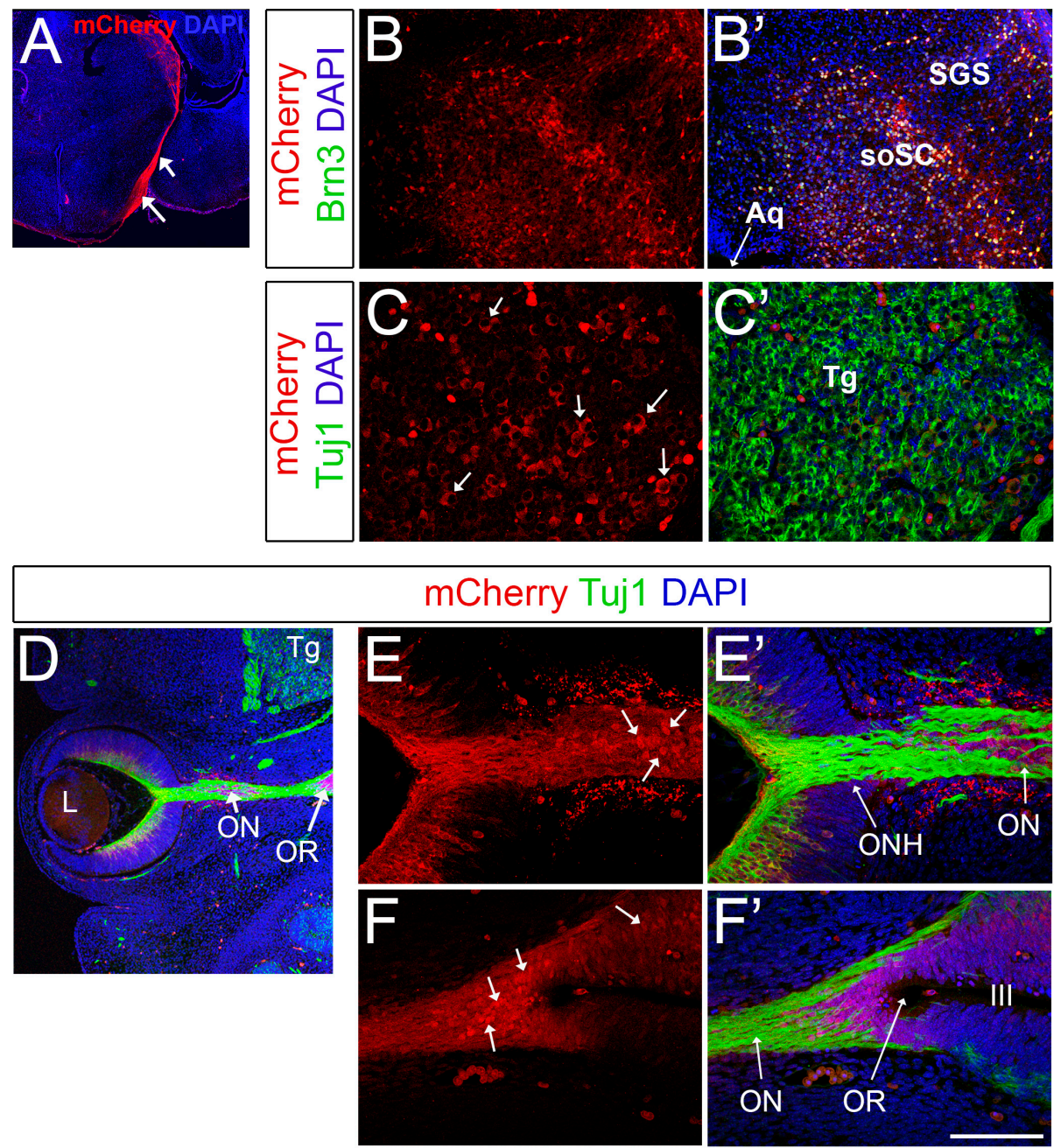

\section{API}

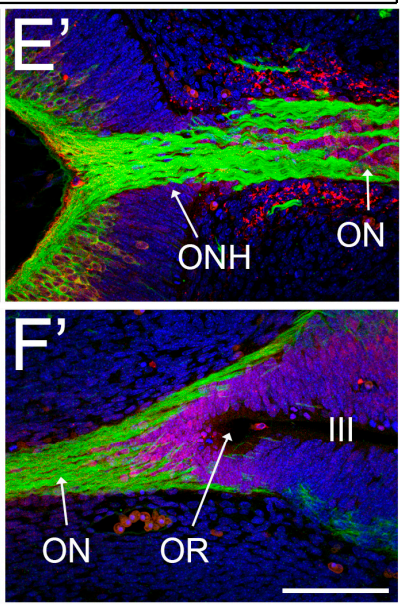

Figure 4. Brn3b-mCherry expression in other regions of the CNS. (A) Optic tracts at P0 visualized by mCherry staining (white arrows). (B, $\left.\mathbf{B}^{\prime}\right)$ Co-localization experiments with mCherry (red) and pan-Brn3 (green) antibodies at P0. (C, $\left.\mathbf{C}^{\prime}\right)$ Co-localization with mCherry (red) and Tuj1 (green) in the trigeminal ganglia at E13.5. Arrows indicate mCherry+ Tuj+ neurons. (D) Low magnification image of a horizontal E13.5 whole-head section. E-F') White arrows indicate mCherry+ Tuj1- cells present in the optic stalk (E) and optic recess (F). Aq: Aqueduct. soSC: stratum opticum of the Superior Colliculus. SGS: Stratum Griseum Superficiale. Tg: Trigeminal ganglion. L: Lens. ONH: Optic Nerve Head. OR: optic recess. III: 3rd ventricle. Scale bar: 100 microns in $C, C^{\prime}, E, E^{\prime}$ and F, $F^{\prime}, 200$ microns in B, $B^{\prime}, 300$ microns in $\mathrm{D}$, and 500 microns in $\mathrm{A}$. 
Surprisingly, during the course of these experiments we observed mCherry expression in cells of the optic stalk (Figure 4D-F' and Figure S2) and in neuroepithelial cells of the optic recess (Figure 4F) at E13.5. The optic stalk is the structure that connects the developing eye to the forebrain and constitutes the conduit along which the RGC axons grow; later in development, the optic stalk becomes the neuroglial sheath that surrounds the optic nerve. Interestingly, at this embryonic stage, both the optic stalk and the optic recess, which forms the boundary region between the optic vesicle, hypothalamus and telencephalon [70], are made of actively dividing neuroepithelial cells that are Pax $2+$ and PCNA+ (Figure S2A). This mCherry expression is intriguing since generally Brn3b is expressed in post-mitotic neurons. However, several reports indicate that Brn3b is expressed at very early stages of development, and also in the developing gonad tissues and germline cells [49,71,72].

In future experiments, it will be interesting to investigate the potential expression of Brn3b in the optic stalk, and to further discriminate any non-cell autonomous roles for Brn3b in optic nerve development as Brn3b-knockouts display axonal disorganization and dysfunction of RGC projections [37]. Alternatively, the presence of mCherry in the optic stalk may reflect important cellular interactions between the optic nerve axons and the neuroepithelial cells of the developing stalk such as material exchange or phagocytosis processes. Previously, transcellular degradation of axonal components by adjacent astrocytes in the optic nerve has been reported in adult mice and in frogs [73,74]. In the same direction, microglial-mediated engulfment of Brn3+ RGCs leading to the presence of Brn3-labeled fragments inside microglial cells has been observed in the embryonic retina [75]. This evidence supports previous reports indicating that a wave of RGC death at early embryonic stages regulates retinal homeostasis [75-77]. Since RGC axons reach the optic nerve $24-48 \mathrm{~h}$ after birth [78], it is possible that mechanisms of cell debris clearance, including mCherry+ axonal fragments, are taking place in the developing optic stalk. Notably, since mCherry is not as sensitive as GFP to the $\mathrm{pH}$ changes that occur in phagocytic vacuoles, our Brn3b-mCherry strain offers an ideal tool to investigate some of these open questions.

\subsection{In Vivo Imaging of $m$ Cherry+ RGCs}

Live imaging of RGCs requires relatively abundant levels of endogenous fluorescence. To address whether Brn3b-mCherry could be used as a tool to monitor RGCs in vivo, we performed noninvasive SLO using our custom multimodal mouse retinal imaging system [79]. Reflectance (Figure 5A,C) and fluorescence images (Figure 5B,D) were collected from 8-12-week-old mice $(n=3)$. Remarkably, we were able to clearly detect mCherry in the living mouse retina, indicating that the intensity of mCherry fluorescence is sufficient for in vivo imaging and longitudinal assessment of RGC status in the same animal over its lifespan. Cell counts from SLO images showed that $1139+/-87.88 \mathrm{mCherry}+$ cells $/ \mathrm{mm}^{2}$ (mean $+/-\mathrm{SD}, n=3$ retinas) are visible with our imaging conditions.

In vivo imaging of RGC disease modeling has the potential to transform mouse RGC disease model research. The specificity of mCherry expression combined with its long-term presence in RGCs makes this reporter mouse an excellent tool for studying RGC disease models and treatment interventions. 


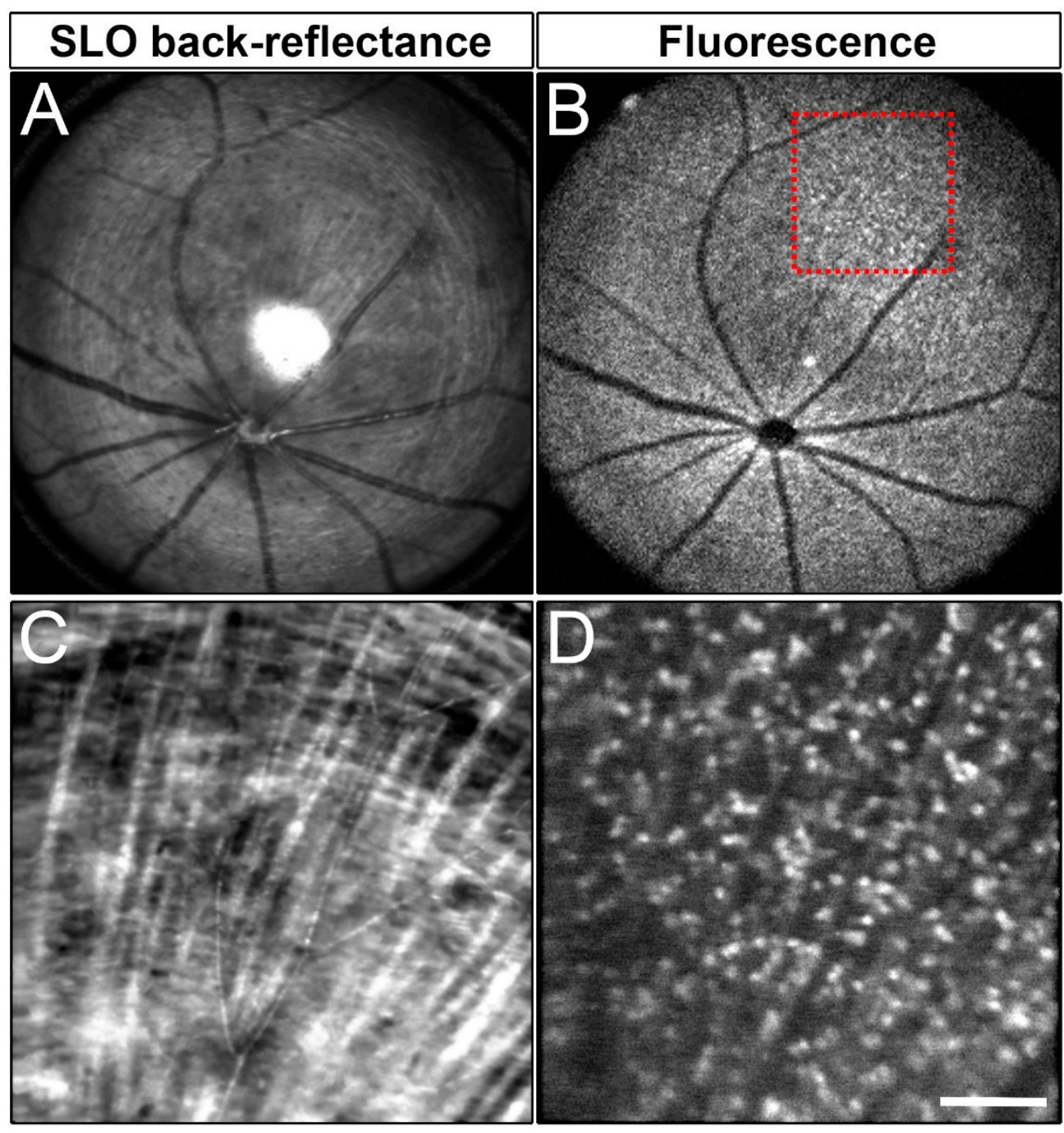

Figure 5. SLO imaging of a Brn3b-mCherry adult retina. (A) SLO back reflectance of a roughly $2 \mathrm{~mm}$ width of an adult Brn3b-mCherry adult retina. (B) Fluorescent signal from the same region shown in A. (C) SLO back-reflectance image of the region of interest marked by a red square in B. (D) Fluorescent signal from the red square marked in B. Scale bars: 400 microns in A and B, and 100 microns in C and D.

\section{Conclusions}

Currently, standard methods to visualize RGCs require sacrificing experimental animals for staining/labeling or are not RGC-specific (e.g., conventional OCT imaging or Thy1-YFP imaging using SLO). Therefore, they are not ideal for monitoring RGCs in living animals and to assess glaucomatous disease progression in real-time. In this report, we have developed a new mouse strain in which all Brn3b-expressing cells express the mCherry fluorescent protein without interfering with normal Brn3b function. In the retina of both adult and developing Brn3b-mCherry mice, mCherry is specifically expressed in a large proportion of RGCs. Furthermore, the level of mCherry expression is sufficient for us to detect RGCs using non-invasive methods in live animals (SLO). Therefore, this new mouse line can be used for developmental studies and, if combined with existing glaucoma models, will enable longitudinal monitoring of RGCs using the fluorescent channel of SLO. Interestingly, a widespread decrease in gene expression, including Brn3, has been reported in glaucoma models [80,81]. This decline in Brn3 and other genes correlates with retrograde axonal transport deficiencies and degeneration. Therefore, Brn3b levels and consequently mCherry will not necessarily reflect cell loss in experimental models of glaucoma but it is a convenient readout of the early stages of RGC degeneration. We 
believe this tool will greatly facilitate the validation of new therapies and neuroprotection strategies for glaucomatous degenerations.

\section{Materials and Methods}

\subsection{Animals}

All mice husbandry and handling were in accordance with protocols approved by the University of California Davis Animal Care and Use Committee (IACUC protocol \# 19413, approved on 12July2016), which strictly adheres to all NIH guidelines and satisfies the Association for Research in Vision and Ophthalmology guidelines for animal use. The Brn3b-mCherry CRISPR knock-in mouse line was generated by Biocytogen (Worcester, MA, USA) in the C57BL/6N background. We have not performed whole-genome sequencing to screen for off-target effects but we have not detected any abnormalities, viability, fertility or any developmental problems (4 different generations have been analyzed to date). For all the embryonic analyses, the morning of the vaginal plug was considered E0.5. The animals are currently being bred to a different background to avoid the Rd8 mutation present in the C57BL/6N background. We will make this line available upon request to the scientific research community.

\subsection{Immunohistochemistry}

For cryosection, embryonic whole heads and P0 dissected eyes were collected and fixed for $30 \mathrm{~min}$ at $4{ }^{\circ} \mathrm{C}$ in $4 \%$ Paraformaldehyde (PFA, Cat \# 15714, Electron Microscopy Sciences for $32 \%$ stock, Hatfield, PA, USA). Following fixation, tissues were cryopreserved by sequential gradients of $10 \%$, $20 \%, 30 \%$ sucrose (tissues were maintained in each solution until they sink), and finally a mixture of half $30 \%$ sucrose and half O.C.T. (Tissue-Tek ${ }^{\circledR}$ O.C.T. Compound, Sakura ${ }^{\circledR}$ Finetek, Alphen aan den Rijn, Netherlands. Cat \# 4583). Tissues were finally embedded in O.C.T., quickly frozen using dry ice, and stored at $-80^{\circ} \mathrm{C}$ until sectioning. For paraffin samples, eyes were collected and frozen in dry-ice chilled propane, and freeze-substituted with methanol-acetic acid at $-80^{\circ} \mathrm{C}$, as described previously [82], transferred to ethanol and embedded in paraffin. Paraffin sections were deparaffinized using Xylene, and further rehydrated. After de-paraffinizing, tissues were washed with PBS, and antigen retrieval was performed with Sodium Citrate Buffer (10mM Sodium Citrate, $0.05 \%$ Tween20, $\mathrm{pH}$ 6.0). Briefly, the slides were placed in a microwave-safe vessel in the Sodium Citrate Buffer and the microwave was set to full power until the solution boiled. The samples were allowed to cool down and were then rinsed 5 times with PBS. Subsequently, all tissue was blocked in $10 \%$ Normal Donkey Serum (NDS) in Phosphate Buffered Saline (PBS)-0.1\% Triton X-100, and the samples were incubated with primary antibodies diluted in fresh blocking solution overnight at $4^{\circ} \mathrm{C}$. Primary antibodies used include: Goat anti-Brn3 (Santa Cruz, Dallas, TX, USA, \#SC-6026, 1:100), Mouse anti-Tuj1 (Biolegend, San Diego, CA, USA, \#801201, 1:500), Rabbit anti-mCherry (Novus Biologicals, Centennial, CO, USA, \#NBP2-25157, 1:500), Goat anti-mCherry (Acris Antibodies, Rockville, MD, USA. \#AB0040-200, 1:500), Guinea Pig anti-RBPMS (Phosphosolutions, Aurora, CO, USA, \#1832-RBPMS, 1:500), Rabbit anti-Sncg (generous gift from Nick Marsh-Arsmtrong, Princeton, NJ, USA, 1:10,000), Rabbit anti-Atoh7 (Novus Biologicals, \#88639, 1:200), anti-Pax2 (Biolegend \#901001, 1:1000), anti-PCNA (Invitrogen, Rockford, IL, USA, \#13-3900, 1:100). Next, tissues were rinsed 5 times with PBS and incubated with Alexa Fluor secondary antibodies (Thermo Fisher Scientific, Rockford, IL, USA) in blocking solution. All tissues were counterstained with 4',6-diamidino-2-phenylindole (DAPI). The sections were rinsed with PBS-0.1\% Triton and mounted for microscopy with Fluoromount-G (Southern Biotech, Birmingham, AL, USA). Most images were obtained with a 20× oil objective and captured with an Olympus FV1000 confocal microscope. High-magnification images were obtained with a 40× oil objective. Images were assembled in Adobe Photoshop and Illustrator. Brightness and contrast were similarly adjusted to all samples. 


\subsection{Retinal Ganglion Cell Counts}

Adult retinas were flat-mounted and stained for mCherry and RBPMS $(n=4$ mice from two different generations). RBPMS labels all RGCs and thus was used as the denominator to count the total number of RGCs in the retina. The percentage of RGCs labeled was measured as the total number of mCherry positive cells over RBPMS positive cells. For each retina, at least 3 pictures from different regions of the eye (ventral, dorsal and central) were taken, quantified and averaged. To calculate mCherry+ cell size, digital images of $250 \times 250 \mu \mathrm{m}^{2}$ of flat-mounted retinas were processed to set intensity and background levels, and mCherry+ cell diameters were calculated using Fiji, considering diameter as the longest distance between any two points on a cell's perimeter.

\subsection{In-Vivo Retina Cellular Imaging}

For in vivo retinal imaging experiments, mice were anesthetized with the inhalational anesthetic isoflurane $\left(2-3 \%\right.$ in $\left.\mathrm{O}_{2}\right)$, and their pupils were dilated with medical grade tropicamide and phenylephrine. A contact lens and gel (GenTeal Tears, Alcon, Fort Worth, TX, USA) was used to maintain the cornea transparency during in vivo retinal imaging [83]. Mouse body temperature was maintained with a temperature-controlled blanket under the animal to prevent cooling of mouse body and development of a cold-cataract. The mouse head was stabilized by a customized bite-bar connected with positioning stage.

A custom rodent scanning laser ophthalmoscopy (SLO) detection channel of custom multimodal mouse retinal imaging instrument [79] was used to image back reflected and fluorescence signal from the mouse retina, with excitation light from an OBIS LX 561nm laser (Coherent Inc., U.S.), and a long-pass filter (BLP02-561R, Semrock, Rochester, New York, USA) to select the emission light for mCherry-expressing cells. The power at the mouse pupil was $\sim 300 \mu \mathrm{W}$, and the beam diameter at the mouse pupil was $\sim 0.5 \mathrm{~mm}$ which offers a lateral resolution of $2.9 \mu \mathrm{m}$ [84].

The mouse retina was first imaged with full field-of-view (FOV) of 51 degrees, corresponding to $\sim 2 \mathrm{~mm}$ on the mouse retina, to allow search for the region of interested (ROI). Then a $3 \times$ zoom-in region was selected and imaged with higher density sampling. For each ROI, a total of 100 serial SLO images, including both reflectance and fluorescence, were collected. The serial images were further registered to using ImageJ TurboReg plugin with 'Rigidbody' transformation [85], and then averaged for display.

Supplementary Materials: Supplementary materials can be found at http://www.mdpi.com/1422-0067/20/12/ 2903/s1.

Author Contributions: Data curation, A.M.M., P.Z., R.J.Z. and A.L.T.; Formal analysis, A.M.M., Y.M.-A., S.K.C., P.Z., R.J.Z. and A.L.T.; Funding acquisition, A.L.T.; Methodology, A.M.M., Y.M.-A., P.Z., R.J.Z., and A.L.T.; Project administration, A.L.T.; Supervision, A.L.T.; Writing—original draft, A.M.M. and A.L.T.; Writing—review \& editing, A.M.M., R.J.Z. and A.L.T.

Funding: This work was supported by National Institutes of Health Grant R01EY026942 and by the Glaucoma Research Foundation Catalyst for a Cure grant to A.L.T., and by the National Institutes of Health T32 Vision Science Training grant 4T32EY015387 to A.M.M. We also benefit from the National Eye Institute Core Facilities grant P30 EY012576.

Acknowledgments: We thank all the members of the La Torre lab for helpful comments on the manuscript. We also thank Edward Pugh, Andy Ishida, Nadean Brown, Nick Marsh-Armstrong, Tom Glaser, and Eric Miller for their insightful advice and generosity with reagents.

Conflicts of Interest: The authors declare no conflict of interest. 


\section{References}

1. Dhande, O.S.; Huberman, A.D. Retinal ganglion cell maps in the brain: Implications for visual processing. Curr. Opin. Neurobiol. 2014, 24, 133-142. [CrossRef] [PubMed]

2. Berson, D.M. Retinal ganglion cell types and their central projections. In The Senses: A Comprehensive Reference (Vision 1); Albright, T.D., Masland, R., Eds.; Elsevier Books: St. Louis, MO, USA, 2008; Volume 1, pp. 491-520.

3. Rheaume, B.A.; Jereen, A.; Bolisetty, M.; Sajid, M.S.; Yang, Y.; Renna, K.; Sun, L.; Robson, P.; Trakhtenberg, E.F. Single cell transcriptome profiling of retinal ganglion cells identifies cellular subtypes. Nat. Commun 2018, 9 , 2759. [CrossRef] [PubMed]

4. Sanes, J.R.; Masland, R.H. The types of retinal ganglion cells: Current status and implications for neuronal classification. Annu. Rev. Neurosci. 2015, 38, 221-246. [CrossRef] [PubMed]

5. Erskine, L.; Herrera, E. Connecting the retina to the brain. ASN Neuro 2014, 6. [CrossRef] [PubMed]

6. Quigley, H.A.; Broman, A.T. The number of people with glaucoma worldwide in 2010 and 2020. Br. J. Ophthalmol. 2006, 90, 262-267. [CrossRef] [PubMed]

7. Calkins, D.J.; Lambert, W.S.; Formichella, C.R.; McLaughlin, W.M.; Sappington, R.M. The Microbead Occlusion Model of Ocular Hypertension in Mice. Methods Mol. Biol. 2018, 1695, 23-39. [CrossRef] [PubMed]

8. Sappington, R.M.; Carlson, B.J.; Crish, S.D.; Calkins, D.J. The microbead occlusion model: A paradigm for induced ocular hypertension in rats and mice. Investig. Ophthalmol. Vis. Sci. 2010, 51, 207-216. [CrossRef]

9. Urcola, J.H.; Hernandez, M.; Vecino, E. Three experimental glaucoma models in rats: Comparison of the effects of intraocular pressure elevation on retinal ganglion cell size and death. Exp. Eye Res. 2006, 83, 429-437. [CrossRef]

10. Shareef, S.R.; Garcia-Valenzuela, E.; Salierno, A.; Walsh, J.; Sharma, S.C. Chronic ocular hypertension following episcleral venous occlusion in rats. Exp. Eye Res. 1995, 61, 379-382. [CrossRef]

11. Morrison, J.C.; Moore, C.G.; Deppmeier, L.M.; Gold, B.G.; Meshul, C.K.; Johnson, E.C. A rat model of chronic pressure-induced optic nerve damage. Exp. Eye Res. 1997, 64, 85-96. [CrossRef]

12. Levkovitch-Verbin, H.; Quigley, H.A.; Martin, K.R.; Valenta, D.; Baumrind, L.A.; Pease, M.E. Translimbal laser photocoagulation to the trabecular meshwork as a model of glaucoma in rats. Investig. Ophthalmol. Vis. Sci. 2002, 43, 402-410.

13. Levkovitch-Verbin, H.; Harris-Cerruti, C.; Groner, Y.; Wheeler, L.A.; Schwartz, M.; Yoles, E. RGC death in mice after optic nerve crush injury: Oxidative stress and neuroprotection. Investig. Ophthalmol. Vis. Sci. 2000, 41, 4169-4174.

14. Berkelaar, M.; Clarke, D.B.; Wang, Y.C.; Bray, G.M.; Aguayo, A.J. Axotomy results in delayed death and apoptosis of retinal ganglion cells in adult rats. J. Neurosci. 1994, 14, 4368-4374. [CrossRef] [PubMed]

15. Jakobs, T.C.; Libby, R.T.; Ben, Y.; John, S.W.; Masland, R.H. Retinal ganglion cell degeneration is topological but not cell type specific in DBA/2J mice. J. Cell Biol. 2005, 171, 313-325. [CrossRef] [PubMed]

16. Libby, R.T.; Anderson, M.G.; Pang, I.H.; Robinson, Z.H.; Savinova, O.V.; Cosma, I.M.; Snow, A.; Wilson, L.A.; Smith, R.S.; Clark, A.F.; et al. Inherited glaucoma in DBA/2J mice: Pertinent disease features for studying the neurodegeneration. Vis. Neurosci. 2005, 22, 637-648. [CrossRef] [PubMed]

17. Smith, R.S.; Zabaleta, A.; Kume, T.; Savinova, O.V.; Kidson, S.H.; Martin, J.E.; Nishimura, D.Y.; Alward, W.L.; Hogan, B.L.; John, S.W. Haploinsufficiency of the transcription factors FOXC1 and FOXC2 results in aberrant ocular development. Hum. Mol. Genet. 2000, 9, 1021-1032. [CrossRef] [PubMed]

18. Libby, R.T.; Smith, R.S.; Savinova, O.V.; Zabaleta, A.; Martin, J.E.; Gonzalez, F.J.; John, S.W. Modification of ocular defects in mouse developmental glaucoma models by tyrosinase. Science 2003, 299, 1578-1581. [CrossRef]

19. Huang, D.; Swanson, E.A.; Lin, C.P.; Schuman, J.S.; Stinson, W.G.; Chang, W.; Hee, M.R.; Flotte, T.; Gregory, K.; Puliafito, C.A.; et al. Optical coherence tomography. Science 1991, 254, 1178-1181. [CrossRef]

20. Vuong, L.N.; Hedges, T.R., 3rd. Ganglion cell layer complex measurements in compressive optic neuropathy. Curr. Opin. Ophthalmol. 2017, 28, 573-578. [CrossRef]

21. Werner, J.S.; Keltner, J.L.; Zawadzki, R.J.; Choi, S.S. Outer retinal abnormalities associated with inner retinal pathology in nonglaucomatous and glaucomatous optic neuropathies. Eye 2011, 25, 279-289. [CrossRef]

22. Werkmeister, R.M.; Cherecheanu, A.P.; Garhofer, G.; Schmidl, D.; Schmetterer, L. Imaging of retinal ganglion cells in glaucoma: Pitfalls and challenges. Cell Tissue Res. 2013, 353, 261-268. [CrossRef] [PubMed] 
23. Feng, G.; Mellor, R.H.; Bernstein, M.; Keller-Peck, C.; Nguyen, Q.T.; Wallace, M.; Nerbonne, J.M.; Lichtman, J.W.; Sanes, J.R. Imaging neuronal subsets in transgenic mice expressing multiple spectral variants of GFP. Neuron 2000, 28, 41-51. [CrossRef]

24. Huberman, A.D.; Manu, M.; Koch, S.M.; Susman, M.W.; Lutz, A.B.; Ullian, E.M.; Baccus, S.A.; Barres, B.A. Architecture and activity-mediated refinement of axonal projections from a mosaic of genetically identified retinal ganglion cells. Neuron 2008, 59, 425-438. [CrossRef] [PubMed]

25. Huberman, A.D.; Wei, W.; Elstrott, J.; Stafford, B.K.; Feller, M.B.; Barres, B.A. Genetic identification of an On-Off direction-selective retinal ganglion cell subtype reveals a layer-specific subcortical map of posterior motion. Neuron 2009, 62, 327-334. [CrossRef] [PubMed]

26. Kim, I.J.; Zhang, Y.; Yamagata, M.; Meister, M.; Sanes, J.R. Molecular identification of a retinal cell type that responds to upward motion. Nature 2008, 452, 478-482. [CrossRef] [PubMed]

27. Yonehara, K.; Ishikane, H.; Sakuta, H.; Shintani, T.; Nakamura-Yonehara, K.; Kamiji, N.L.; Usui, S.; Noda, M. Identification of retinal ganglion cells and their projections involved in central transmission of information about upward and downward image motion. PLoS ONE 2009, 4, e4320. [CrossRef] [PubMed]

28. Rivlin-Etzion, M.; Zhou, K.; Wei, W.; Elstrott, J.; Nguyen, P.L.; Barres, B.A.; Huberman, A.D.; Feller, M.B. Transgenic mice reveal unexpected diversity of on-off direction-selective retinal ganglion cell subtypes and brain structures involved in motion processing. J. Neurosci. 2011, 31, 8760-8769. [CrossRef]

29. Rodriguez, A.R.; de Sevilla Muller, L.P.; Brecha, N.C. The RNA binding protein RBPMS is a selective marker of ganglion cells in the mammalian retina. J. Comp. Neurol. 2014, 522, 1411-1443. [CrossRef]

30. Gan, L.; Xiang, M.; Zhou, L.; Wagner, D.S.; Klein, W.H.; Nathans, J. POU domain factor Brn-3b is required for the development of a large set of retinal ganglion cells. Proc. Natl. Acad. Sci. USA 1996, 93, 3920-3925. [CrossRef]

31. Zhou, H.; Yoshioka, T.; Nathans, J. Retina-derived POU-domain factor-1: A complex POU-domain gene implicated in the development of retinal ganglion and amacrine cells. J. Neurosci. 1996, 16, 2261-2274. [CrossRef]

32. Erkman, L.; McEvilly, R.J.; Luo, L.; Ryan, A.K.; Hooshmand, F.; O'Connell, S.M.; Keithley, E.M.; Rapaport, D.H.; Ryan, A.F.; Rosenfeld, M.G. Role of transcription factors Brn-3.1 and Brn-3.2 in auditory and visual system development. Nature 1996, 381, 603-606. [CrossRef] [PubMed]

33. Brown, N.L.; Patel, S.; Brzezinski, J.; Glaser, T. Math5 is required for retinal ganglion cell and optic nerve formation. Development 2001, 128, 2497-2508. [PubMed]

34. Wang, S.W.; Kim, B.S.; Ding, K.; Wang, H.; Sun, D.; Johnson, R.L.; Klein, W.H.; Gan, L. Requirement for math5 in the development of retinal ganglion cells. Genes Dev. 2001, 15, 24-29. [CrossRef] [PubMed]

35. Xiang, M.; Zhou, L.; Macke, J.P.; Yoshioka, T.; Hendry, S.H.; Eddy, R.L.; Shows, T.B.; Nathans, J. The Brn-3 family of POU-domain factors: Primary structure, binding specificity, and expression in subsets of retinal ganglion cells and somatosensory neurons. J. Neurosci. 1995, 15, 4762-4785. [CrossRef] [PubMed]

36. Gan, L.; Wang, S.W.; Huang, Z.; Klein, W.H. POU domain factor Brn-3b is essential for retinal ganglion cell differentiation and survival but not for initial cell fate specification. Dev. Biol. 1999, 210, 469-480. [CrossRef] [PubMed]

37. Badea, T.C.; Cahill, H.; Ecker, J.; Hattar, S.; Nathans, J. Distinct roles of transcription factors brn3a and brn3b in controlling the development, morphology, and function of retinal ganglion cells. Neuron 2009, 61, 852-864. [CrossRef] [PubMed]

38. Xiang, M. Requirement for Brn-3b in early differentiation of postmitotic retinal ganglion cell precursors. Dev. Biol. 1998, 197, 155-169. [CrossRef]

39. Wang, S.W.; Mu, X.; Bowers, W.J.; Kim, D.S.; Plas, D.J.; Crair, M.C.; Federoff, H.J.; Gan, L.; Klein, W.H. $\mathrm{Brn} 3 \mathrm{~b} / \mathrm{Brn} 3 \mathrm{c}$ double knockout mice reveal an unsuspected role for Brn3c in retinal ganglion cell axon outgrowth. Development 2002, 129, 467-477.

40. Erkman, L.; Yates, P.A.; McLaughlin, T.; McEvilly, R.J.; Whisenhunt, T.; O'Connell, S.M.; Krones, A.I.; Kirby, M.A.; Rapaport, D.H.; Bermingham, J.R.; et al. A POU domain transcription factor-dependent program regulates axon pathfinding in the vertebrate visual system. Neuron 2000, 28, 779-792. [CrossRef]

41. Wu, F.; Kaczynski, T.J.; Sethuramanujam, S.; Li, R.; Jain, V.; Slaughter, M.; Mu, X. Two transcription factors, Pou4f2 and Isl1, are sufficient to specify the retinal ganglion cell fate. Proc. Natl. Acad. Sci. USA 2015, 112, E1559-E1568. [CrossRef] 
42. Sajgo, S.; Ali, S.; Popescu, O.; Badea, T.C. Dynamic expression of transcription factor Brn3b during mouse cranial nerve development. J. Comp. Neurol. 2016, 524, 1033-1061. [CrossRef] [PubMed]

43. Turner, E.E.; Jenne, K.J.; Rosenfeld, M.G. Brn-3.2: A Brn-3-related transcription factor with distinctive central nervous system expression and regulation by retinoic acid. Neuron 1994, 12, 205-218. [CrossRef]

44. Hodgkins, A.; Farne, A.; Perera, S.; Grego, T.; Parry-Smith, D.J.; Skarnes, W.C.; Iyer, V. WGE: A CRISPR database for genome engineering. Bioinformatics 2015, 31, 3078-3080. [CrossRef] [PubMed]

45. Zheng, D.; Yang, X.; Sheng, D.; Yu, D.; Liang, G.; Guo, L.; Xu, M.; Hu, X.; He, D.; Yang, Y.; et al. Pou4f2-GFP knock-in mouse line: A model for studying retinal ganglion cell development. Genesis 2016, 54, 534-541. [CrossRef] [PubMed]

46. Zubair, M.; Watanabe, E.; Fukada, M.; Noda, M. Genetic labelling of specific axonal pathways in the mouse central nervous system. Eur. J. Neurosci. 2002, 15, 807-814. [CrossRef] [PubMed]

47. Badea, T.C.; Williams, J.; Smallwood, P.; Shi, M.; Motajo, O.; Nathans, J. Combinatorial expression of Brn3 transcription factors in somatosensory neurons: Genetic and morphologic analysis. J. Neurosci. 2012, 32, 995-1007. [CrossRef]

48. Ghinia, M.G.; Novelli, E.; Sajgo, S.; Badea, T.C.; Strettoi, E. Brn3a and Brn3b knockout mice display unvaried retinal fine structure despite major morphological and numerical alterations of ganglion cells. J. Comp. Neurol. 2019, 527, 187-211. [CrossRef] [PubMed]

49. Sajgo, S.; Ghinia, M.G.; Shi, M.; Liu, P.; Dong, L.; Parmhans, N.; Popescu, O.; Badea, T.C. Dre-Cre sequential recombination provides new tools for retinal ganglion cell labeling and manipulation in mice. PLoS ONE 2014, 9, e91435. [CrossRef]

50. Shaner, N.C.; Steinbach, P.A.; Tsien, R.Y. A guide to choosing fluorescent proteins. Nat. Methods 2005, 2, 905-909. [CrossRef]

51. Triplett, J.W.; Wei, W.; Gonzalez, C.; Sweeney, N.T.; Huberman, A.D.; Feller, M.B.; Feldheim, D.A. Dendritic and axonal targeting patterns of a genetically-specified class of retinal ganglion cells that participate in image-forming circuits. Neural Dev. 2014, 9, 2. [CrossRef]

52. Sluch, V.M.; Davis, C.H.; Ranganathan, V.; Kerr, J.M.; Krick, K.; Martin, R.; Berlinicke, C.A.; Marsh-Armstrong, N.; Diamond, J.S.; Mao, H.Q.; et al. Differentiation of human ESCs to retinal ganglion cells using a CRISPR engineered reporter cell line. Sci. Rep. 2015, 5, 16595. [CrossRef] [PubMed]

53. Daniszewski, M.; Senabouth, A.; Nguyen, Q.H.; Crombie, D.E.; Lukowski, S.W.; Kulkarni, T.; Sluch, V.M.; Jabbari, J.S.; Chamling, X.; Zack, D.J.; et al. Single cell RNA sequencing of stem cell-derived retinal ganglion cells. Sci. Data 2018, 5, 180013. [CrossRef] [PubMed]

54. Nadal-Nicolas, F.M.; Jimenez-Lopez, M.; Salinas-Navarro, M.; Sobrado-Calvo, P.; Alburquerque-Bejar, J.J.; Vidal-Sanz, M.; Agudo-Barriuso, M. Whole number, distribution and co-expression of brn3 transcription factors in retinal ganglion cells of adult albino and pigmented rats. PLoS ONE 2012, 7, e49830. [CrossRef] [PubMed]

55. Sajgo, S.; Ghinia, M.G.; Brooks, M.; Kretschmer, F.; Chuang, K.; Hiriyanna, S.; Wu, Z.; Popescu, O.; Badea, T.C. Molecular codes for cell type specification in Brn3 retinal ganglion cells. Proc. Natl. Acad. Sci. USA 2017, 114, E3974-E3983. [CrossRef] [PubMed]

56. Oron-Karni, V.; Farhy, C.; Elgart, M.; Marquardt, T.; Remizova, L.; Yaron, O.; Xie, Q.; Cvekl, A.; Ashery-Padan, R. Dual requirement for Pax6 in retinal progenitor cells. Development 2008, 135, 4037-4047. [CrossRef] [PubMed]

57. Cepko, C.L.; Austin, C.P.; Yang, X.; Alexiades, M.; Ezzeddine, D. Cell fate determination in the vertebrate retina. Proc. Natl. Acad. Sci. USA 1996, 93, 589-595. [CrossRef] [PubMed]

58. Rapaport, D.H.; Dorsky, R.I. Inductive competence, its significance in retinal cell fate determination and a role for Delta-Notch signaling. Semin. Cell Dev. Biol. 1998, 9, 241-247. [CrossRef]

59. Harris, W.A. Cellular diversification in the vertebrate retina. Curr. Opin. Genet. Dev. 1997, 7, 651-658. [CrossRef]

60. Barton, K.M.; Levine, E.M. Expression patterns and cell cycle profiles of PCNA, MCM6, cyclin D1, cyclin A2, cyclin B1, and phosphorylated histone H3 in the developing mouse retina. Dev. Dyn. 2008, 237, 672-682. [CrossRef]

61. Prasov, L.; Glaser, T. Dynamic expression of ganglion cell markers in retinal progenitors during the terminal cell cycle. Mol. Cell. Neurosci. 2012, 50, 160-168. [CrossRef] 
62. Pacal, M.; Bremner, R. Induction of the ganglion cell differentiation program in human retinal progenitors before cell cycle exit. Dev. Dyn. 2014, 243, 712-729. [CrossRef] [PubMed]

63. Brzezinski, J.A.t.; Prasov, L.; Glaser, T. Math5 defines the ganglion cell competence state in a subpopulation of retinal progenitor cells exiting the cell cycle. Dev. Biol. 2012, 365, 395-413. [CrossRef] [PubMed]

64. Aparicio, J.G.; Hopp, H.; Choi, A.; Mandayam Comar, J.; Liao, V.C.; Harutyunyan, N.; Lee, T.C. Temporal expression of CD184(CXCR4) and CD171(L1CAM) identifies distinct early developmental stages of human retinal ganglion cells in embryonic stem cell derived retina. Exp. Eye Res. 2017, 154, 177-189. [CrossRef] [PubMed]

65. Miesfeld, J.B.; Glaser, T.; Brown, N.L. The dynamics of native Atoh7 protein expression during mouse retinal histogenesis, revealed with a new antibody. Gene Expr. Patterns 2018, 27, 114-121. [CrossRef] [PubMed]

66. Surguchov, A.; McMahan, B.; Masliah, E.; Surgucheva, I. Synucleins in ocular tissues. J. Neurosci. Res. 2001, 65, 68-77. [CrossRef] [PubMed]

67. Surgucheva, I.; Surguchov, A. Gamma-synuclein: Cell-type-specific promoter activity and binding to transcription factors. J. Mol. Neurosci. 2008, 35, 267-271. [CrossRef] [PubMed]

68. Surgucheva, I.; Weisman, A.D.; Goldberg, J.L.; Shnyra, A.; Surguchov, A. Gamma-synuclein as a marker of retinal ganglion cells. Mol. Vis. 2008, 14, 1540-1548.

69. Byun, H.; Kwon, S.; Ahn, H.J.; Liu, H.; Forrest, D.; Demb, J.B.; Kim, I.J. Molecular features distinguish ten neuronal types in the mouse superficial superior colliculus. J. Comp. Neurol. 2016, 524, 2300-2321. [CrossRef]

70. Affaticati, P.; Yamamoto, K.; Rizzi, B.; Bureau, C.; Peyrieras, N.; Pasqualini, C.; Demarque, M.; Vernier, P. Identification of the optic recess region as a morphogenetic entity in the zebrafish forebrain. Sci. Rep. 2015, 5, 8738. [CrossRef]

71. Jameson, S.A.; Natarajan, A.; Cool, J.; DeFalco, T.; Maatouk, D.M.; Mork, L.; Munger, S.C.; Capel, B. Temporal transcriptional profiling of somatic and germ cells reveals biased lineage priming of sexual fate in the fetal mouse gonad. PLoS Genet. 2012, 8, e1002575. [CrossRef]

72. Budhram-Mahadeo, V.; Moore, A.; Morris, P.J.; Ward, T.; Weber, B.; Sassone-Corsi, P.; Latchman, D.S. The closely related POU family transcription factors Brn-3a and Brn-3b are expressed in distinct cell types in the testis. Int. J. Biochem. Cell Biol. 2001, 33, 1027-1039. [CrossRef]

73. Davis, C.H.; Kim, K.Y.; Bushong, E.A.; Mills, E.A.; Boassa, D.; Shih, T.; Kinebuchi, M.; Phan, S.; Zhou, Y.; Bihlmeyer, N.A.; et al. Transcellular degradation of axonal mitochondria. Proc. Natl. Acad. Sci. USA 2014, 111, 9633-9638. [CrossRef] [PubMed]

74. Mills, E.A.; Davis, C.H.; Bushong, E.A.; Boassa, D.; Kim, K.Y.; Ellisman, M.H.; Marsh-Armstrong, N. Astrocytes phagocytose focal dystrophies from shortening myelin segments in the optic nerve of Xenopus laevis at metamorphosis. Proc. Natl. Acad. Sci. USA 2015, 112, 10509-10514. [CrossRef] [PubMed]

75. Frade, J.M.; Rodriguez-Tebar, A.; Barde, Y.A. Induction of cell death by endogenous nerve growth factor through its p75 receptor. Nature 1996, 383, 166-168. [CrossRef] [PubMed]

76. de la Rosa, E.J.; de Pablo, F. Cell death in early neural development: Beyond the neurotrophic theory. Trends Neurosci. 2000, 23, 454-458. [CrossRef]

77. Cuadros, M.A.; Rios, A. Spatial and temporal correlation between early nerve fiber growth and neuroepithelial cell death in the chick embryo retina. Anat Embryol. 1988, 178, 543-551. [CrossRef]

78. Farah, M.H.; Easter, S.S., Jr. Cell birth and death in the mouse retinal ganglion cell layer. J. Comp. Neurol. 2005, 489, 120-134. [CrossRef] [PubMed]

79. Zhang, P.; Zam, A.; Jian, Y.; Wang, X.; Li, Y.; Lam, K.S.; Burns, M.E.; Sarunic, M.V.; Pugh, E.N., Jr.; Zawadzki, R.J. In vivo wide-field multispectral scanning laser ophthalmoscopy-optical coherence tomography mouse retinal imager: Longitudinal imaging of ganglion cells, microglia, and Muller glia, and mapping of the mouse retinal and choroidal vasculature. J. Biomed. Opt. 2015, 20, 126005. [CrossRef]

80. Soto, I.; Oglesby, E.; Buckingham, B.P.; Son, J.L.; Roberson, E.D.; Steele, M.R.; Inman, D.M.; Vetter, M.L.; Horner, P.J.; Marsh-Armstrong, N. Retinal ganglion cells downregulate gene expression and lose their axons within the optic nerve head in a mouse glaucoma model. J. Neurosci. 2008, 28, 548-561. [CrossRef]

81. Huang, W.; Fileta, J.; Guo, Y.; Grosskreutz, C.L. Downregulation of Thy1 in retinal ganglion cells in experimental glaucoma. Curr. Eye Res. 2006, 31, 265-271. [CrossRef]

82. Sun, N.; Shibata, B.; Hess, J.F.; FitzGerald, P.G. An alternative means of retaining ocular structure and improving immunoreactivity for light microscopy studies. Mol. Vis. 2015, 21, 428-442. [PubMed] 
83. Zhang, P.; Mocci, J.; Wahl, D.J.; Meleppat, R.K.; Manna, S.K.; Quintavalla, M.; Muradore, R.; Sarunic, M.V.; Bonora, S.; Pugh, E.N.; et al. Effect of a contact lens on mouse retinal in vivo imaging: Effective focal length changes and monochromatic aberrations. Exp. Eye Res. 2018, 172, 86-93. [CrossRef] [PubMed]

84. Zhang, P.; Goswami, M.; Zam, A.; Pugh, E.N.; Zawadzki, R.J. Effect of scanning beam size on the lateral resolution of mouse retinal imaging with SLO. Opt. Lett. 2015, 40, 5830-5833. [CrossRef] [PubMed]

85. Thevenaz, P.; Ruttimann, U.E.; Unser, M. A pyramid approach to subpixel registration based on intensity. IEEE Trans. Image Process. 1998, 7, 27-41. [CrossRef] [PubMed]

(C) 2019 by the authors. Licensee MDPI, Basel, Switzerland. This article is an open access article distributed under the terms and conditions of the Creative Commons Attribution (CC BY) license (http://creativecommons.org/licenses/by/4.0/). 